\title{
Towards Reducing Climate Change Impact Assessment Process Uncertainty
}

\author{
Abhishek Gaur ${ }^{1} \cdot$ Slobodan P. Simonovic ${ }^{1}$ \\ Received: 18 November 2014 / Accepted: 18 March 2015 /Published online: 15 April 2015 \\ (C) Springer International Publishing Switzerland 2015
}

\begin{abstract}
Three different sources of process-based uncertainty in climate change impact studies have been identified. It has been demonstrated that uncertainty can arise from: a) differences in the process approach, b) differences in the methods used in each step of the process, and c) differences in the space, time and distribution scales considered for analysis. The discussion of possible reasons behind the observed differences in climate change assessment analyses follows. It has been recommended that the selection of robust methods, which not only perform well on historical timeline but also keep the climate models changes intact, is the key to reduce process-based uncertainty in climate projections. Further, it is advised that future climate projections be analysed at all space, time, distribution coordinates located within the domain of interest in order to obtain a comprehensive picture of the changes projected by the climate models.
\end{abstract}

Keywords Climate change $\cdot$ Impact assessment $\cdot$ Uncertainty $\cdot$ Robustness

\section{Introduction}

Climate change is impacting the global environment and will continue to do so in the future (Stocker et al. 2013; Solomon et al. 2007). Therefore it is not surprising that a large number of climate change impact studies have been performed to estimate local (e.g., Gaur and Simonovic 2013), regional (e.g., Dankers and Feyen 2009) and global (e.g., Hirabayashi et al. 2013) scale climatic changes in the future. General aim of any climate change impact assessment study is to estimate the climatic variable of interest, taking into consideration the uncertainty associated with future projections. However, significant process-based differences exist between different climate change impact studies conducted up to now. For instance, a comparison of methodologies followed by two global, two continental and two catchment

Abhishek Gaur

abhishek.gaur1988@gmail.com

1 Facility for Intelligent Decision Support, Department of Civil and Environmental Engineering, Western University, London, Ontario N6A 3K7, Canada 
scale climate change impact studies on flow extremes is provided in Table 1. We will focus our discussion on the steps that lead to the downscaling of climate model data. These steps are followed in all studies that aim at analysing impacts of climate change at a local scale, and hence, the discussion is relevant to a wide range of climate change impact assessment studies. Typically, three steps are involved in a climate change impact analysis process: 1) selection of climate model projections, 2) bias-correction, and 3) downscaling of climate model projections.

The first step involves the selection of climate models as well as emission scenarios for analysis. Multiple climate models and emission scenarios have been identified in the 4th assessment (AR4) and the 5th assessment (AR5) reports of the Intergovernmental Panel on Climate Change (IPCC) (Stocker et al. 2013; Solomon et al. 2007). It has been recommended that the projections from every model should be considered equally plausible in the future. Climate model evaluation and selection has been performed in the past (Perkins et al. 2007; Maxino et al. 2008; Lapp et al. 2008; Barrow and Yu 2005) to fulfil one of the following two objectives: 1) to choose from a range of projections made by the GCMs for analysis or 2) to encompass the range of changes projected by the multi-model ensemble. The former approach can be performed by considering averaged, weighted-average or selected projections for analysis (Tebaldi and Knutti 2007). This approach has been extensively used for designing climate-informed water resource systems in the past, in spite of the fact that it compromises the total uncertainty associated with GCM projections. The latter approach can be performed by using methods like scatter-plot selection (Mortsch 2011; Garraway 2011; Lapp et al. 2008; Barrow and $\mathrm{Yu}$ 2005). In the scatter-plot method, GCM-scenario combinations most likely to produce hydro-climatic weather extremes are selected. Cold-dry, cold-wet, hot-dry and hot-wet scenarios in terms of mean projected changes are selected for analysis.

Table 1 Differences in methodologies among climate change impact assessment studies carried out at different spatial scales - selected examples

\begin{tabular}{|c|c|c|c|c|}
\hline Reference & Scale of study & Variable & Process & Method \\
\hline Hirabayashi et al. (2013) & Global & High flow & $\begin{array}{l}\text { Selection of climate } \\
\text { model projections }\end{array}$ & Arbitrary \\
\hline Hirabayashi et al. (2009) & Global & $\begin{array}{l}\text { High and } \\
\text { low flow }\end{array}$ & $\begin{array}{l}\text { Selection of climate } \\
\text { model projections }\end{array}$ & Arbitrary \\
\hline \multirow[t]{2}{*}{ Dankers and Feyen (2009) } & \multirow[t]{2}{*}{ Continental } & \multirow[t]{2}{*}{ High flow } & $\begin{array}{l}\text { Selection of climate } \\
\text { model projections }\end{array}$ & Arbitrary \\
\hline & & & Downscaling & Dynamic \\
\hline Schneider et al. (2012) & Continental & Mean flow & $\begin{array}{l}\text { Selection of climate } \\
\text { model projections }\end{array}$ & Arbitrary \\
\hline \multirow[t]{2}{*}{ Das and Simonovic (2012) } & \multirow[t]{2}{*}{ Catchment } & \multirow[t]{2}{*}{ High flow } & $\begin{array}{l}\text { Selection of climate } \\
\text { model projections }\end{array}$ & Arbitrary \\
\hline & & & Downscaling & $\begin{array}{c}\text { Statistical (KNN-CAD } \\
\text { weather generator) }\end{array}$ \\
\hline \multirow[t]{3}{*}{ Gaur and Simonovic (2013) } & \multirow[t]{3}{*}{ Catchment } & \multirow[t]{3}{*}{ High flow } & $\begin{array}{l}\text { Selection of climate } \\
\text { model projections }\end{array}$ & Arbitrary \\
\hline & & & Bias-correction & $\begin{array}{l}\text { Statistical Bias } \\
\text { Correction (SBC) }\end{array}$ \\
\hline & & & Downscaling & $\begin{array}{l}\text { Statistical (M3EB } \\
\text { weather generator) }\end{array}$ \\
\hline
\end{tabular}


The purpose of bias correction step is to modify climate model data in a way that the correlation between model and observed data increases. Since mostly statistical methods are employed for doing so, this step is believed to interfere with the climatology projected by physically based climate models which take into account complex hydro-meteorological, atmospheric and land-surface interactions prevalent within the earth's system (Vannitsem 2011). Many methods, ranging from those correcting just the means to those correcting entire distributions of climate data, have been used in the past for performing this step (Ines and Hansen 2006; Piani et al. 2010).

Downscaling is a method used to estimate high spatial resolution climate information from low spatial resolution GCM output. Two different classes of downscaling methods have been identified in the literature: 1) statistical downscaling, and 2) dynamic downscaling. The former methods, first develop a relationship between large scale atmospheric variables and local scale climate variables, and then, use the relationship to obtain future local scale climate information whereas the latter approach simulates the local scale climate in a physically based way using boundary conditions provided by large scale climate models (Solomon et al. 2007).

From Table 1, it can be noticed that the process followed while performing these studies differs in almost every single case-study although the general aim of quantifying the changes in hydrological extremes in the future remained the same in each study. These differences range from the approach followed to the number of methods employed in each step. For instance, while performing flood frequency analysis on flow extremes at a global scale, Hirabayashi et al. (2013) performed the selection of climate model projections, used the projections directly to obtain flows using a hydrologic model, and then, performed statistical analysis of the flow peaks. On the other hand, Gaur and Simonovic (2013) performed bias-correction and downscaling on climate model projections before using them to obtain flows. The approach of each of these climate change impact assessment studies is framed to suit the needs of the analysis being performed without taking into consideration its impact on future climatic projections. Differences in the approaches of climate change impact assessment studies can be considered as one source of uncertainty associated with future climate projections.

Different methods have been used in each step of the approach as listed in Table 1. For instance, Hirabayashi et al. (2013) used 11 GCMs for making future flow projections, while Das and Simonovic (2012) used projections from 6 GCMs to do so. The GCMs as well as emission scenarios used in both studies are also different. While the former study used projections made by the following climate models: BCC-CSM1.1, CCCma-CanESM2, CMCC-CM, CNRMCM5, CSIRO-Mk.3.6.0, GFDL-ESM2G, INM-CM4, MIROC5, MPI-ESM-LR, MRICGCM3, NCC-NorESM1-M under four Representative Concentration Pathways (RCPs), i.e., RCP2.6, RCP4.5, RCP6.0 and RCP8.5 (Vuuren et al. 2011) to estimate the future flows, the latter study used projections made by climate models: CGCM3T47, CGCMsT63, CSIROMk3.5, GISS-AOM, MIROC3.2HIRES, MIROC3.2MEDRES under three Special Report Emission Scenarios (SRES), i.e., A1B, A2 and B1 to estimate flows. The selection of climate model projections in these studies has been performed in an arbitrary manner and has mostly been guided by the availability of climate model data necessary for performing hydrologic modelling in the area of interest. Uncertainty associated with the use of multiple climate models, use of multiple bias-correction methodologies, and use of multiple downscaling techniques has been analysed at different regions across the globe and their significant contributions towards the future projected climate is well recognised and documented (Knutti and Sedlacek 2013; Chen et al. 2011a, b; Eisner et al. 2012). The uncertainty associated with future projections is in general higher if larger ensembles of methods are used to perform each step of 
climate change impact analysis. Therefore, methods used in each step of a climate change impact assessment study may be another important factor that influences the projected future climate.

Changes projected by climate models, as well as outputs from different methods used while performing climate change impact analysis process, also vary with the spatial, temporal and distributional scale considered for the analysis. Evidence of this behaviour has been found in the past in the case of climate models (Sakaguchi et al. 2012a, b) as well as bias-correction methods (Haerter et al. 2011). The objective of this study is to demonstrate the uncertainty in climate projections introduced through all the above mentioned differences in the assessment approaches, related methods and our choice of space, time and distributional scales for analysis. The analysis performed and the methods used while performing the analysis have been explained in section 2. The area at which the analysis is performed as well as the datasets used are described next in section 3. Results obtained from the analysis are presented in section 4. Possible reasons behind these differences have been identified and possible ways of reducing them are presented and discussed in section 5 .

\section{Analysis Performed and Methods Used}

In this study, a range of analysis is performed to demonstrate the uncertainty in climate model projections that is introduced from previously discussed process-based sources. A summary of the analysis performed is summarised in Table 2. For achieving the first objective, climate model projections obtained before and after performing each individual step of the approach have been compared. Changes projected by climate models have been accessed in this study using change factors. Change factors are the average changes projected by climate models between historical and future timelines (Anandhi et al. 2011).

For achieving the second objective, climate projections obtained by using two different methods in each step of the approach are compared. Selection of climate model projections has been made using Probability Density Function (PDF) comparison method and scatter-plot method. PDF comparison method compares probability density functions of historical observed and model simulated data and allots a skill score based on the extent of their overlap. This metric has been found to be a simple yet robust indicator of model skill and the methodology has been used in many studies in the past (Maxino et al. 2008; Perkins et al. 2009; Pitman and Perkins 2008). Climate model projections following all three Special Report Emission Scenarios (SRES), i.e., A1B, A2 and B1 (IPCC 2000), are considered for the selected model(s). The scatter-plot method on the other hand aims at encompassing the uncertainty associated with the future projections made by all climate models considered for analysis. Typically, GCM-emission scenario combinations that project hydro-climatically extreme conditions in the future are selected (Lapp et al. 2008; Barrow and Yu 2005). Bias correction has been performed by correcting: a) monthly means, and b) entire distribution of climate data using Statistical Bias Correction (SBC) approach (Piani et al. 2009). In SBC approach, transfer functions are first developed between historically observed and climate model data. These transfer functions are used together with future climate model data to obtain bias-corrected future climate model data. Downscaling is performed following a change factor approach and by using two different weather generators: KNN-CAD (version 4) (King et al. 2012) and Multisite multivariate weather generator model (M3EB) (Srivastav and Simonovic 2014). The former is a semi-parametric weather generator while the latter is a non-parametric type weather generator. 
Table 2 A summary of the analysis performed in this study

\begin{tabular}{|c|c|c|}
\hline Objective & $\begin{array}{l}\text { Scale/step of } \\
\text { uncertainty }\end{array}$ & Analysis performed \\
\hline \multirow[t]{3}{*}{$\begin{array}{l}\text { Uncertainty introduced by } \\
\text { climate change impact } \\
\text { analysis process structure }\end{array}$} & $\begin{array}{l}\text { Selection of } \\
\text { climate model } \\
\text { projections }\end{array}$ & $\begin{array}{l}\text { Comparison of the projected range of change factors } \\
\text { with and without performing this step }\end{array}$ \\
\hline & Bias correction & $\begin{array}{l}\text { Comparison of the projected change factors for a GCM } \\
\text { before and after bias-correction is performed }\end{array}$ \\
\hline & Downscaling & $\begin{array}{l}\text { Comparison of projected change factors for a } \\
\text { GCM before and after downscaling is performed }\end{array}$ \\
\hline \multirow[t]{3}{*}{$\begin{array}{l}\text { Uncertainty introduced by the } \\
\text { use of various methods }\end{array}$} & $\begin{array}{l}\text { Selection of } \\
\text { climate model } \\
\text { projections }\end{array}$ & $\begin{array}{l}\text { Comparison of the projected range of change factors } \\
\text { using: a) PDF comparison method and b) scatter-plot } \\
\text { method }\end{array}$ \\
\hline & Bias correction & $\begin{array}{l}\text { Comparison of future projected precipitation obtained } \\
\text { after bias-correcting a) monthly means b) entire } \\
\text { distribution using SBC approach }\end{array}$ \\
\hline & Downscaling & $\begin{array}{l}\text { Comparison of future precipitation downscaled using a) } \\
\text { KNN-CAD (v4) b) M3EB weather generators }\end{array}$ \\
\hline \multirow[t]{7}{*}{$\begin{array}{l}\text { Uncertainty due to different } \\
\text { space, time and distribution } \\
\text { scales }\end{array}$} & Spatial & $\begin{array}{l}\text { Comparison of model skill obtained at two different } \\
\text { spatial scales: entire Ontario province (ONT) and } \\
\text { region S3 }\end{array}$ \\
\hline & & $\begin{array}{l}\text { Comparison of change factors projected at two } \\
\text { different gauging stations: Apps Mills and Arthur }\end{array}$ \\
\hline & Temporal & $\begin{array}{l}\text { Comparison of model skill obtained at two different } \\
\text { temporal scales: } 1961-2000 \text { and 1981-2000 }\end{array}$ \\
\hline & & $\begin{array}{l}\text { Comparison of change factors projected at Apps Mills } \\
\text { and Arthur considering four different historical } \\
\text { baselines: 1961-1970,1971-1980, 1981-1990 and } \\
\text { 1991-2000 }\end{array}$ \\
\hline & Distributional & $\begin{array}{l}\text { Comparison of hydro-climatic extreme GCM-scenario } \\
\text { combinations selected using scatter-plot method } \\
\text { based on projected changes in a) means and b) } \\
\text { extreme precipitation values }\end{array}$ \\
\hline & & $\begin{array}{l}\text { Comparison of model skill obtained after using two } \\
\text { different weighting schemes: a) uniform and b) } \\
\text { linearly increasing }\end{array}$ \\
\hline & & $\begin{array}{l}\text { Comparison of change factors for Apps Mills and } \\
\text { Arthur projected at each } 10 \text { percentile bin scale }\end{array}$ \\
\hline
\end{tabular}

For achieving the third objective, a comparison of model skills, change factors and hydroclimatical extreme GCM-scenario combinations is made by considering different spatial, temporal and distributional scales. Analysis has been performed at three different spatial scales: point location (Apps Mills $(-80.38,43.13)$ and Arthur $(-80.57,43.82)$ ), regional (S3) and provincial (ONT), at many different time-slices between 1961 and 2000 and by analysing mean and data mean at each 10 percentile bin-scale. Further, for exploring the effects of distributional scale on model skill, calculations were made using two different weighting schemes: uniform and linearly increasing. Under uniform weighting scheme, all percentile bins of data are given equal weight, while under linearly increasing weighting scheme, higher percentile bins are assigned higher weight. This way a higher skill score is assigned to a climate model that is able to simulate the extremes well compared to a model which simulates the lower bin values well. 


\section{Study Area and Datasets Used}

In this study the analysis has been performed on the Grand River at Brantford located in the south-western Ontario, Canada. Grand River originates in the Dundalk and Grand valley region and flows $128 \mathrm{~km}$ southwards to drain into Lake Erie at Port Maitland. The Grand River catchment is the largest among south-western Ontario catchments. It covers approximately $6965 \mathrm{~km}^{2}$ of area and is home for more than 787,000 people (Boyd et al. 2009). The area within Ontario (named as ONT in Fig. 1) as well as that located south of $46^{\circ} \mathrm{N}$ latitude (named as S3 in Fig. 1) were selected for the analyses presented in this paper.

Climate data used in this study include:

- Historically observed daily precipitation and temperature data obtained from the National Climate Data and Information Archive (NCDIA) for the period 1961-2000. Precipitation data for 866 gauging stations and temperature data for 577 gauging stations located across the region S3 of the Ontario province.

- Gridded daily precipitation and mean temperature data projected for historical (19612000) and future timelines (2050s and 2090s) provided by the Coupled Model Intercomparison Project- Phase 3 (CMIP3) of the World Climate Research Programme (WCRP) (Meehl et al. 2007). The 16 CMIP3 GCMs selected on the basis of consistent data

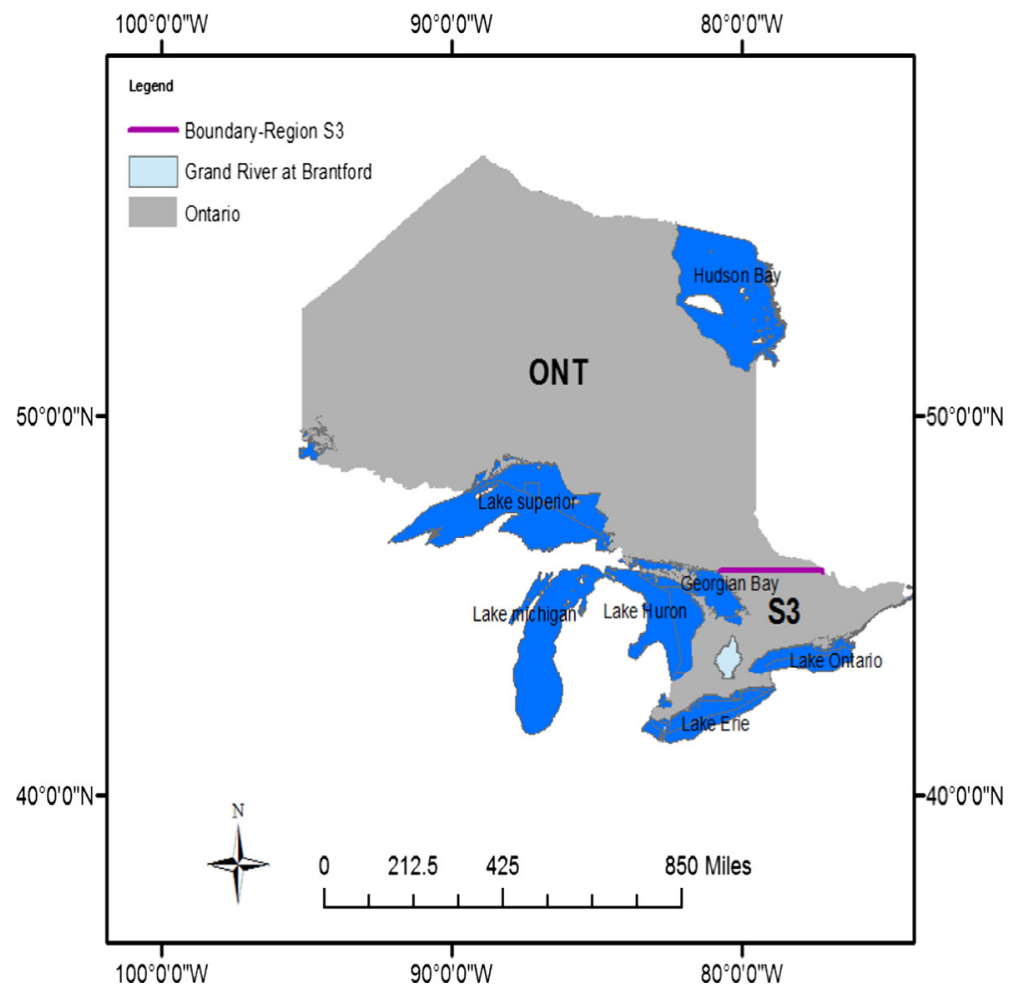

Fig. 1 Geographic settings of the region under study. ONT denotes the entire area located inside the provincial boundaries of Ontario. S3 denotes the area that is located south of $46^{\circ} \mathrm{N}$ latitudes and falls within the Ontario province. The Grand River catchment selected for analysis in this study is also shown 
availability for the historical and future timelines and across the three SRES emission scenarios: A1B, A2 and B1 are listed in Table 3.

\section{Results and Discussion}

\subsection{Uncertainty Introduced by the Climate Change Impact Analysis Approach}

The range of changes projected by GCM(s) varies with the set of GCM-scenario combinations considered for the analysis. Figure 2 illustrates the changes in extreme precipitation and temperature ( $>99$ th percentile) as projected by 16 GCMs used in the analysis. The uncertainty associated with the changes projected by different GCM-emission scenario combinations is visible in the plot. The range of projected changes will clearly be reduced if the projection from any one, or a subset of GCMs, is considered for the analysis. For instance, the best performing GCM across the S3 region obtained according to the PDF comparison approach is CSIROMK3.5. It projects a $12-60 \%$ increase in precipitation extremes as well as an increase of $1-$ $4{ }^{\circ} \mathrm{C}$ in temperature extremes within the region which is significantly less than the overall range projected by all GCMs. Similarly, there is a compromise in the projected uncertainty if the projected changes are simply averaged. The mean change projected by all GCM-scenario combinations in this case is close to $12 \%$ which clearly does not capture the entire range of projections made by all GCM-scenario combinations. Therefore, the selection of GCMs can impact the range of changes projected in the future.

Table 3 Climate models considered in this study

\begin{tabular}{llll}
\hline S.No & Model & \multicolumn{2}{l}{ Atmospheric component resolution } \\
\cline { 2 - 3 } & & Horizontal (lat $\times$ lon) & Vertical (levels) \\
\hline 1 & & $1.9^{\circ} \times 1.9^{\circ}$ & L31 \\
2 & BCCR-BCM2.0, 2005 & $2.8^{\circ} \times 2.8^{\circ}$ & L31 \\
3 & CGCM3.1(T47), 2005 & $1.9^{\circ} \times 1.9^{\circ}$ & L31 \\
4 & CGCM3.1(T63), 2005 & $1.9^{\circ} \times 1.9^{\circ}$ & L45 \\
5 & CNRM-CM3, 2004 & $1.9^{\circ} \times 1.9^{\circ}$ & L18 \\
6 & CSIRO-MK3.0, 2001 & $1.9^{\circ} \times 1.9^{\circ}$ & L18 \\
7 & CSIRO-MK3.5, 2005 & $2.0^{\circ} \times 2.5^{\circ}$ & L24 \\
8 & GFDL-CM2.0, 2005 & $2.0^{\circ} \times 2.5^{\circ}$ & L24 \\
9 & GFDL-CM2.1, 2005 & $4^{\circ} \times 3^{\circ}$ & L12 \\
10 & GISS-AOM, 2004 & $4^{\circ} \times 5^{\circ}$ & L20 \\
11 & GISS-ER, 2004 & $2.8^{\circ} \times 2.8^{\circ}$ & L26 \\
12 & IAP-FGOALS, 2004 & $1.9^{\circ} \times 1.9^{\circ}$ & L18 \\
13 & INGV-ECHAM4, 2005 & $2.5^{\circ} \times 3.75^{\circ}$ & L19 \\
14 & IPSL-CM4, 2005 & $2.8^{\circ} \times 2.8^{\circ}$ & L20 \\
15 & MIROC3.2(medres), 2004 & $1.9^{\circ} \times 1.9^{\circ}$ & L31 \\
\hline & MPI-ECHAM5, 2005 & $2.8^{\circ} \times 2.8^{\circ}$ & L30 \\
\hline
\end{tabular}

Model outputs corresponding to Climate of the Twentieth Century and SRES scenarios A1B, A2 and B1 are included in the analysis 


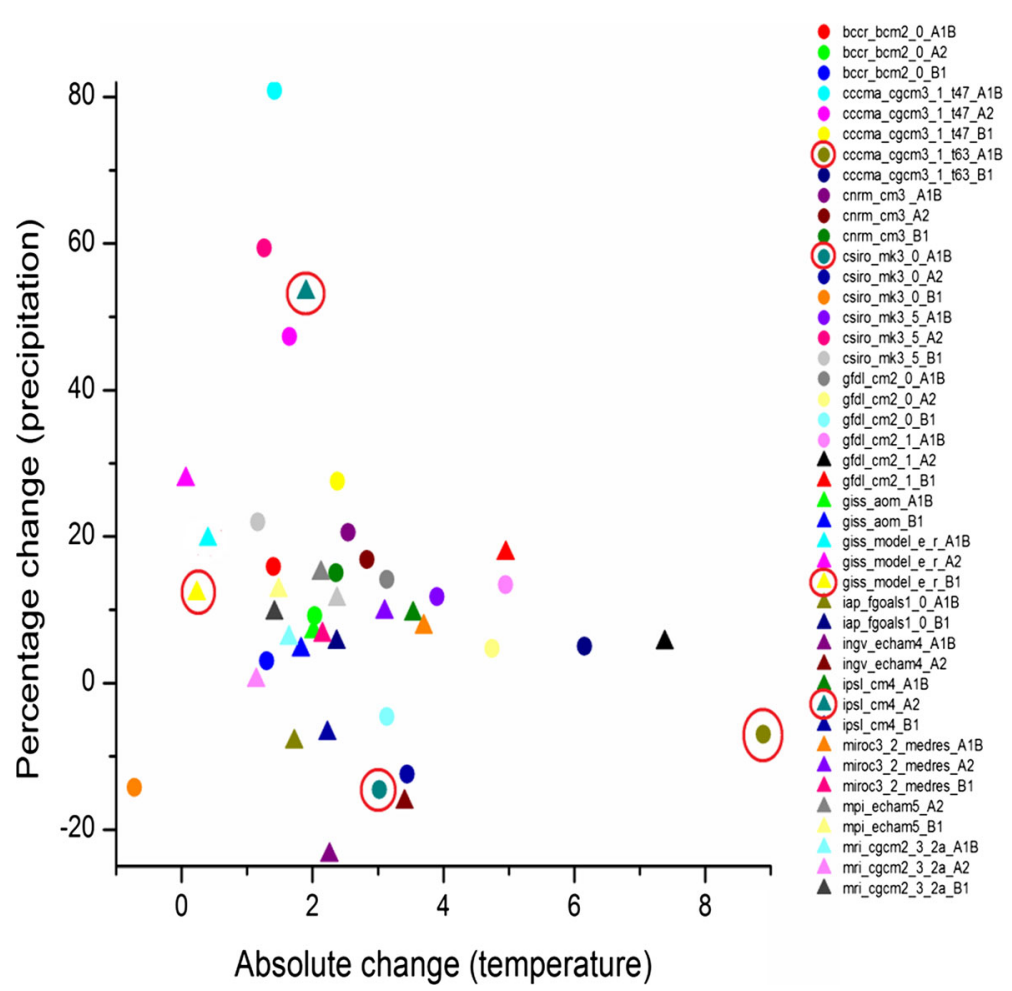

Fig. 2 Dependence of the selection of hydro-climatic extreme scenarios on selected distributional scale. Individual data points correspond to mean changes projected for extreme precipitation (above 99th percentile) whereas the extreme scenarios selected from mean precipitation data are encircled

Change factors derived from a particular GCM are influenced by the bias-correction process. The SBC approach described in section 2 of the paper has been used to bias-correct precipitation projections made by the CSIRO-MK3.5 GCM and SRES A1B emission scenario at all gauging stations located across the Grand River catchment. The bias-correction process used was found to be able to correct model bias efficiently, as shown in Fig. 3a. The precipitation change factors for 2050 s, as projected by the GCM, vary between 1.3 and 1.7 for the bias-corrected case (represented by CF-BC in Fig. 3b) while it stays almost constant at 1.1 for the uncorrected case (represented by CF-Raw in Fig. 3 b). Similar results are obtained for other GCMs when bias-corrected and raw change factor statistics are analysed.

The impact of downscaling step on the projected change factors is found to be less significant than the impact of the bias-correction step. In Fig. 3b, bias-corrected change factors are compared with their downscaled counterparts (represented by CF-BC-DS) for the same GCM. The downscaling is performed using M3EB weather generator. It is found that the choice of downscaling method does impact the changes projected by the GCM, however, their impact is found to be less significant (close to a change factor difference of around 0.1 in this case) as compared to the impact of the bias-correction method choice. It should be noted here though that the downscaling process that we have used in this study is based on a change factor and weather generator approach which is more likely to preserve the projected changes than 
a

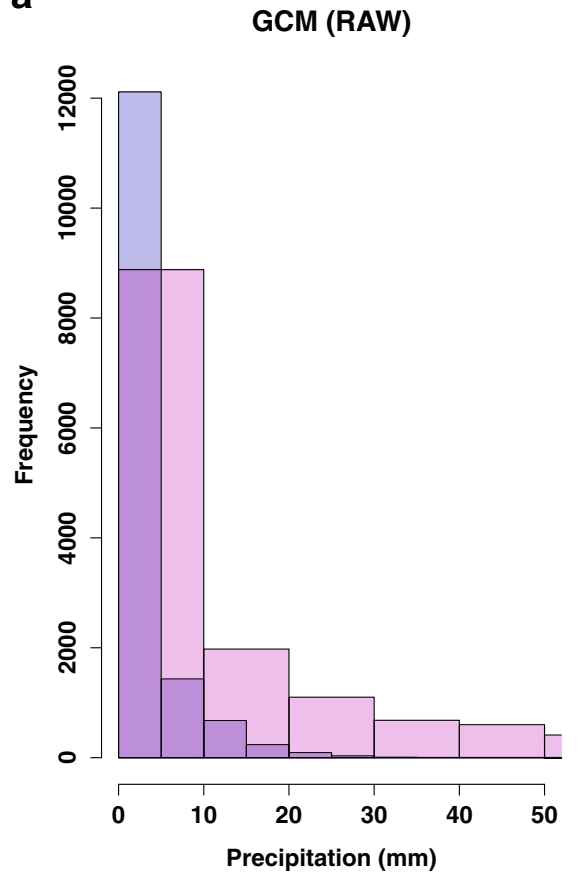

GCM (Bias-Corrected)

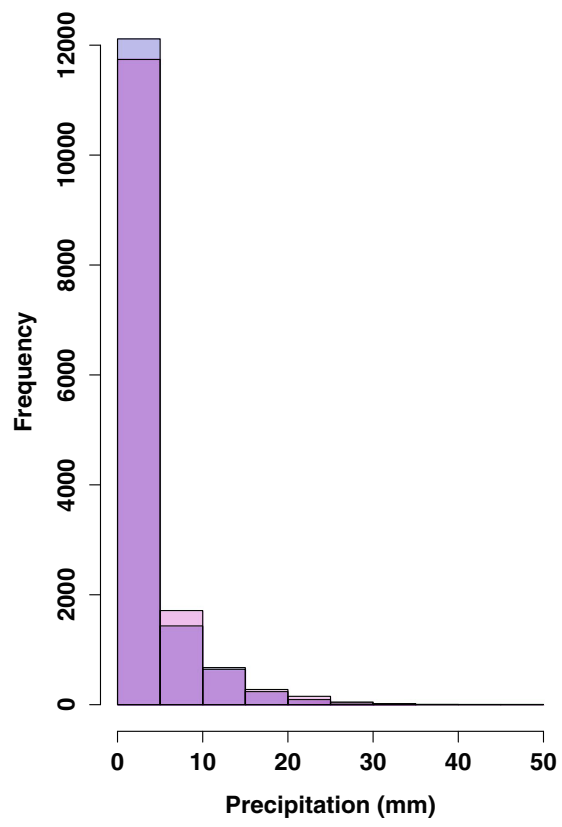

b

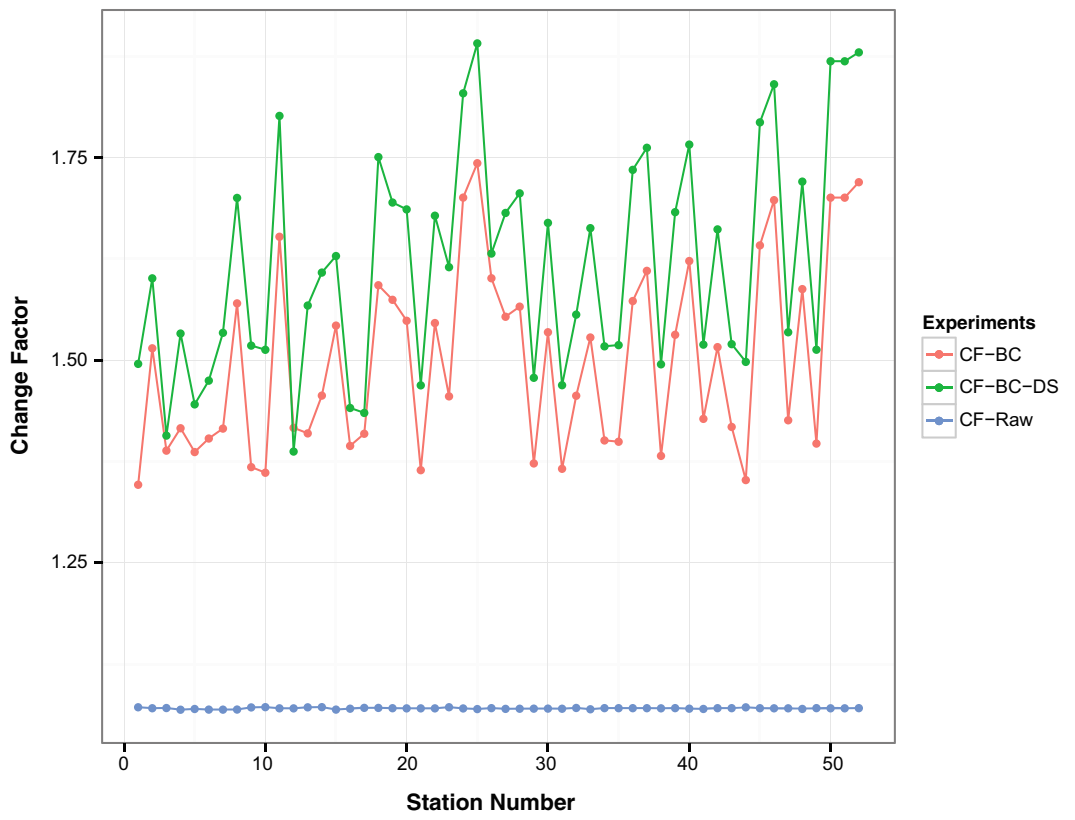

Fig. 3 a Bias correction of daily precipitation observed at a gauging station: Apps Mills using Statistical Bias Correction (SBC) approach. b Change factors projected by a climate model: CSIRO-MK3.5 before and after bias correction. Also shown are the changes projected after bias corrected precipitation data is downscaled using the M3EB weather generator 
other parametric and semi-parametric downscaling approaches. Difference between the results obtained from different downscaling methods can be large (Khan et al. 2006; Taye and Willems 2013) and they are addressed in the following section.

\subsection{Uncertainty Introduced by the Use of Various Methods}

The impact of selection of climate models and emission scenarios is investigated using a comparison between PDF selection method and scatter-plot method. The three top performing climate models obtained from the PDF comparison method are found to be: MRICGCM2.3.2a, INGV-ECHAM4 and CSIRO-MK3.5. It is found that the top model describes $13 \%$ of the total uncertainty introduced by all models, while the top-two models together are able to describe $32 \%$ of the total uncertainty. Interestingly $100 \%$ uncertainty is described when the top three models are considered. On the other hand, almost $100 \%$ uncertainty in the projected change factors is described by the selected emission scenarios obtained using scatterplot and percentile methods. This shows that the method used to select climate model projections can influence the range of changes projected for the future.

Uncertainty is also evident when different bias-correction and downscaling methods are used. Figure 4 compares the results obtained at a precipitation gauging station: Apps Mills $(-80.38,43.13)$ by performing bias-correction on a) monthly means, and b) entire distribution using SBC approach. Although both approaches give similar results in the historical timeline, their future projections carry considerable uncertainty, which is highlighted in yellow in Fig. 4. At the same gauging station, precipitation data is downscaled using change factor approach and two different weather generators: KNN-CAD (version-4) and M3EB (Srivastav and

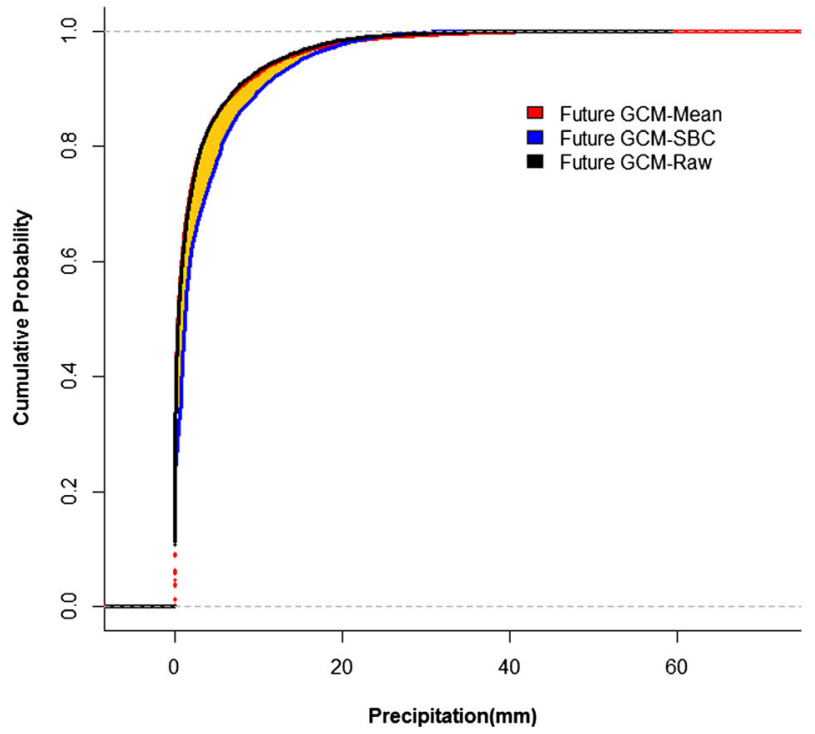

Fig. 4 Future (2046-2065) data projected by a GCM: CSIRO-MK3.5 when bias-corrected for monthly means (denoted as Future GCM-Mean) and entire distribution using Statistical Bias Correction approach (denoted as Future GCM-SBC). For making comparison precipitation projected by the GCM without bias-correction is also shown (denoted as Future-GCM-Raw). Uncertainty in future precipitation projections due to the application of two bias-correction methods is highlighted in yellow 
Simonovic 2014). It can be noted from Fig. 5 that the projections made by both weather generators for the same set of future scaled data differ from each other. The uncertainty associated with projections is found to be more in case of M3EB as compared to KNNCAD weather generator. Projection made by raw GCM data is also shown to highlight the amount of uncertainty that can be introduced just by introduction of two different weather generators in the downscaling process.

\subsection{Uncertainty Due to Different Space, Time and Distribution Scales}

The spatial, temporal and distributional scale selected for the analysis also influence the results obtained in each step of the climate change impact analysis process. A comparison of model skills obtained by considering two different spatial scales (named S3 and ONT), two different time-periods (1961-2000 and 1981-2000) and two different weighting schemes, i.e., uniform and linearly increasing (represented by "U" and " $L$ ", respectively), is presented in Fig. 6. It can be noted that apart from some models (for instance INGV-ECHAM4) which perform well under all spatial, temporal and distributional scales, model skill varies for different experiments conducted. A similar dependency of model skill on spatial and temporal scales have also been obtained in other studies performed at regional and global scales (Sakaguchi et al. 2012a, b).

Impact of changes in the distributional scale is explored on the output of scatter-plot method. In Fig. 2, hydro-climatic extreme scenarios are selected using the changes in means and extremes ( $>99$ percentile) as projected by all GCMs. Individual data points correspond to the percent change in extreme precipitation and absolute change in extreme temperature projected by each climate model-scenario combination. Model-scenario combinations selected based on mean changes are also highlighted to show that the selections made using a particular distributional scale differ from those selected using a different distributional scale.

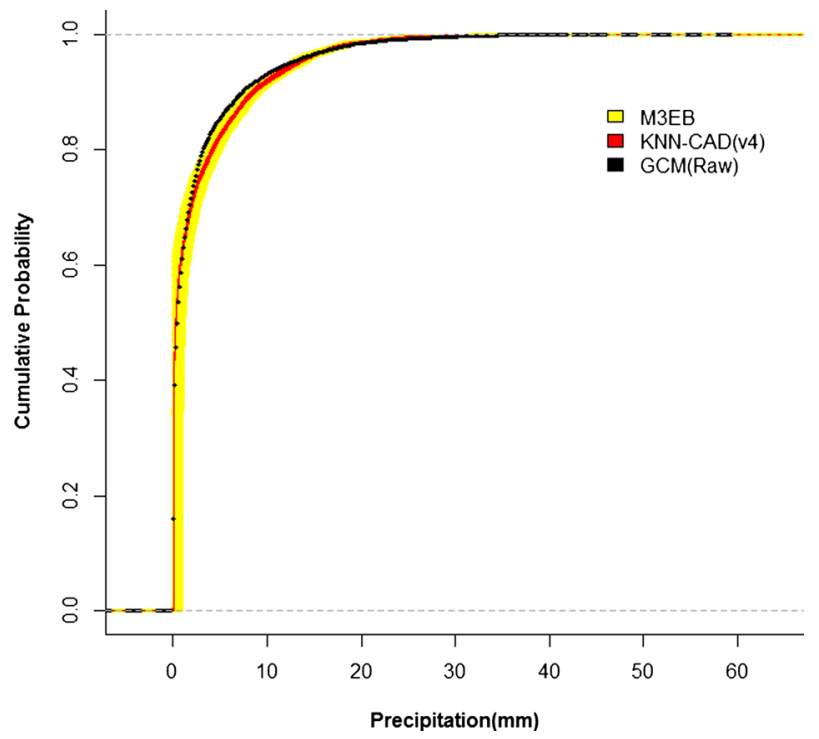

Fig. 5 Uncertainty in future precipitation as projected by two downscaled products of GCM: CSIRO-MK3.5 produced using two weather generators: $\mathrm{KNN}-\mathrm{CAD}(\mathrm{v} 4)$ and $\mathrm{M} 3 \mathrm{~EB}$. A total of twenty realisations are generated by each weather generator. The uncertainty in future projections has been highlighted in yellow 


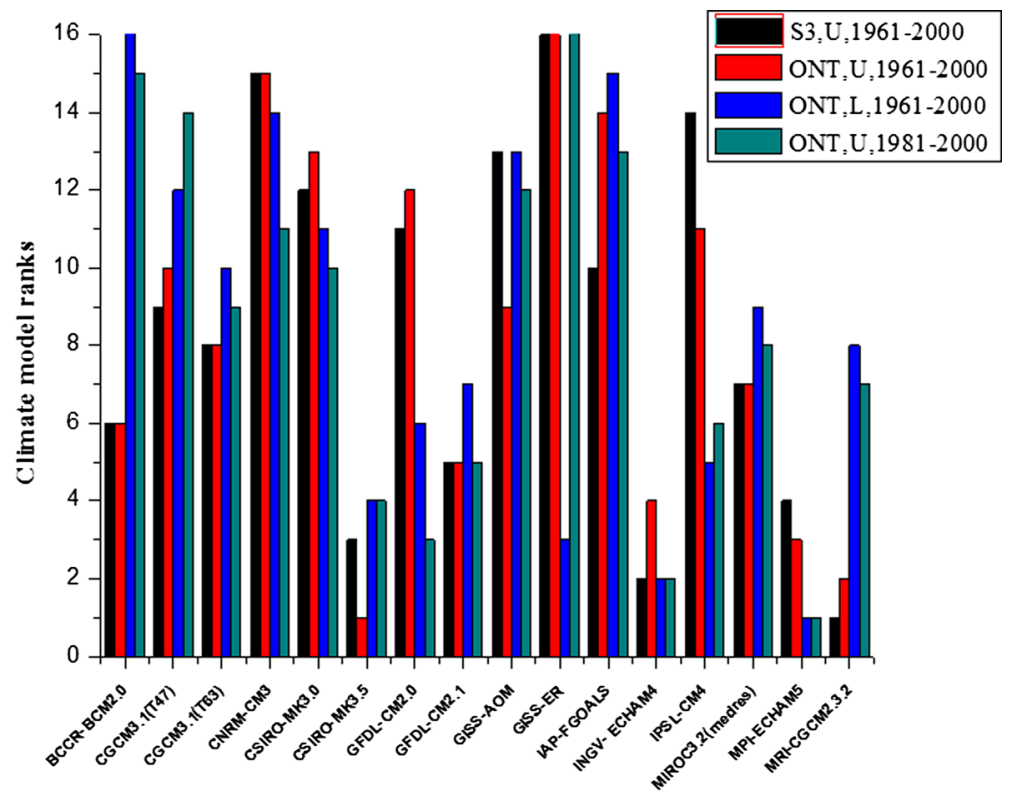

Fig. 6 Climate model rankings obtained by using PDF comparison method for four different experiments with different sets of spatial, temporal and distributional scale combinations. The indices S3 and ONT denotes the spatial extent considered, $U$ and $\mathrm{L}$ denote the weighting applied to different percentile bins and 1961-2000 and 1981-2000 are the time-periods considered

In Fig. 7, change factors projected by a representative GCM, i.e., CSIRO-MK3.5 in 2050s (2046-2065), for selected sets of temporal, spatial and distributional scales are presented. Here, the spatial bin scale has been chosen as local or point location, the temporal bin scale has been chosen as 10 years, and the distributional scale has been chosen as 10 percentile values. Results are presented at two gauging stations: a) Apps Mills, and b) Arthur located
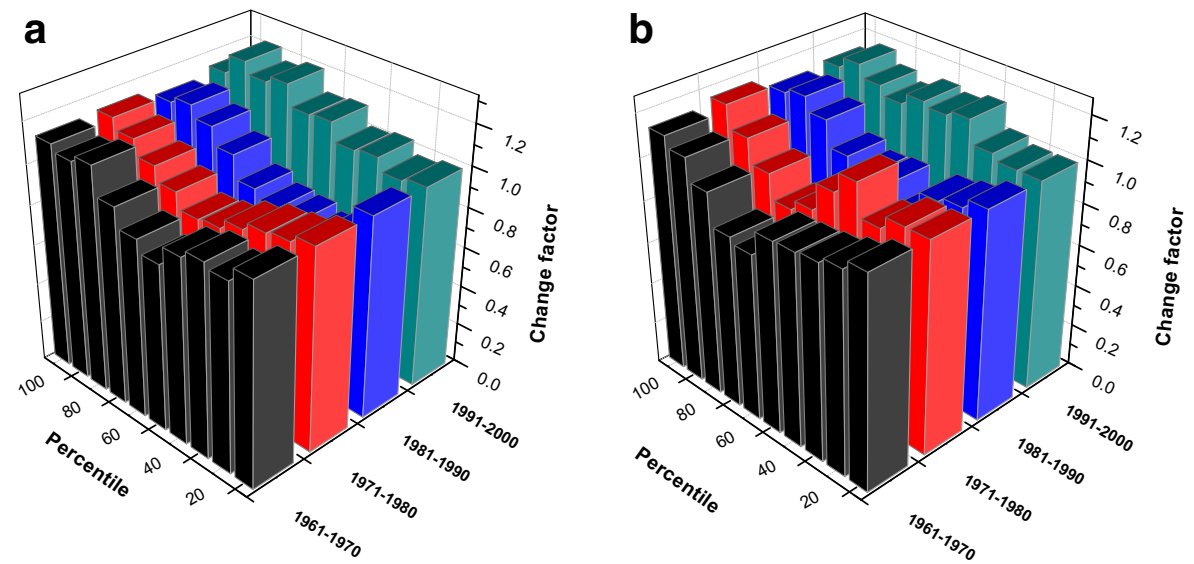

Fig. 7 Precipitation change factors as projected by a CMIP3 GCM: CSIRO-MK3.5 at gauging stations: a Apps Mills and b Arthur for 2050s considering different baseline time-periods and percentile bins 
within the Grand River catchment. The change factors of selected percentile ranges have been calculated considering 1961-1970, 1971-1980, 1981-1990 and 1990-2000 as historical timelines. It can be seen that the change factor values are different for all four timelines considered. Further change factors associated with each percentile bin as well as point locations considered in this analysis are found to be different, suggesting that climate change impact analysis results are a function of the space, time and distribution coordinate selected for analysis.

\section{Conclusions}

This study has identified three process based sources which can introduce uncertainty in future climate projections. It has been highlighted that the state-of-the-art climate change impact studies show inconsistencies in their consideration of the above mentioned sources of uncertainty. Analysis performed in the study demonstrates that the process approach, methods used in each step and space-time-distribution scale selected for analysis can influence future projected climate. Although analysis results presented in this study are obtained for the Ontario province in Canada, similar results can be expected in other regions of the globe as well. Therefore, there is a need for common guidelines which can help researchers across the globe to design consistent climate change impact study processes in the future.

To avoid inconsistencies in the approaches that are adopted to perform climate change impact assessment, it is important that the methods used in each step do not change the projections made by the climate models. If the methods used in each step are not only performing well on historical timeline but are also able to preserve the changes projected by the climate models, all three steps of selection of climate model projection, bias correction and downscaling can be adopted in every study without impacting the changes projected by the climate models. A few recent studies have focussed on this aspect while designing bias-

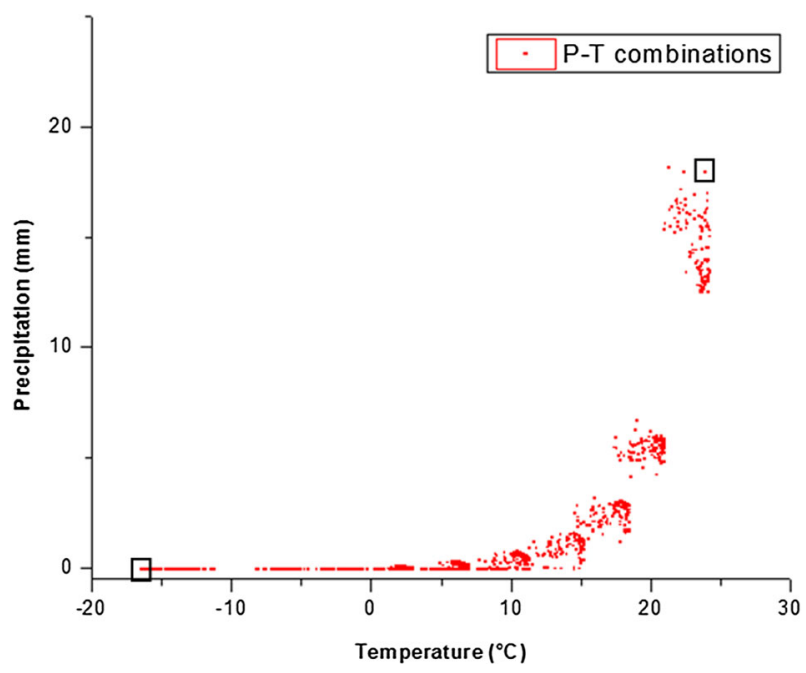

Fig. 8 Space, time and distribution coordinates for the Grand River catchment which are associated with historically observed cold-dry and hot-humid scenarios 
correction methodologies (Hempel et al. 2013) and methodologies for other steps should also be developed keeping in mind the above mentioned criteria.

Uncertainty associated with the usage of multiple methods cannot be fully encompassed because of the ever increasing number of these methods. However the uncertainty associated can be reduced by taking into consideration the projections from robust methods only. Since it is clear that climate change will result in unprecedented climatic conditions in the future, it is important to test methods for robustness under extreme hydro-climatic conditions observed in the past. Here, we demonstrate how we can locate appropriate space, time and distribution scales which represent hydro-climatic extreme conditions within the Grand River catchment over the period 1961-2000. For doing so, first a suitable spatial, temporal and distributional bin size is selected. In our case, we selected point locations as spatial bin size, a decade as temporal bin size and 10 percentile as distribution bin size. Precipitation and temperature values are calculated at each spatial, temporal and distributional coordinate values, and thereafter, used to create a scatter-plot of precipitation and temperature values as shown in Fig. 8. The space, time and distribution coordinates representing dry-cold and hot-humid conditions have been highlighted within black boxes. These coordinate values can be used to evaluate methods for robustness within the catchment.

To reduce the uncertainty associated with the selection of space, time and distribution scales, the analysis should be performed considering all space, time and distribution bins that are located within the domain of interest. In this endeavour, the choice of bin-size will be crucial. It is recommended that it is selected judiciously. The sensitivity of the results would decrease as the bin-size will increase and vice versa. Selection of very large scales may give an averaged picture of the changes while selection of very fine scales can represent unstable changes. A balance between the two should be sought while selecting appropriate space, time and distribution scales for any climate change impact assessment study.

Acknowledgments We acknowledge the World Climate Research Programme's Working Group on Coupled Modeling for producing and making available their CMIP3 model output. Further, we thank Environment Canada for providing daily precipitation and temperature datasets across the Grand River catchment. Further, we thank the two reviewers and the editor who greatly helped towards improving this manuscript by providing detailed and insightful feedback on the original manuscript.

\section{References}

Anandhi A, Frei A, Pierson DC, Schneiderman EM, Zion MS, Lounsbury D, Matonse AH (2011) Examination of change factor methodologies for climate change impact assessment. Water Resour Res 47(3):W03501. doi:10.1029/2010WR009104

Barrow E, Yu G (2005) Climate Scenarios for Alberta. A Report Prepared for the Prairie Adaptation Research Collaborative (PARC) in co-operation with Alberta Environment, 1-73

Boyd D, Cooke S, Yerex W (2009) Exploring Grand-Erie connections: flow, quality and ecology. In 9th Annual Grand River Watershed Water Forum, Cambridge, Ontario: 1-23

Chen J, Brissette FP, Leconte R (2011a) Uncertainty of downscaling method in quantifying the impact of climate change on hydrology. J Hydrol 401(3-4):190-202. doi:10.1016/j.jhydrol.2011.02.020

Chen C, Haerter J, Hagemann S, Piani C (2011b) On the contribution of statistical bias correction to the uncertainty in the projected hydrological cycle. Geophys Res Lett 38:L20403. doi:10.1029/ 2011GL049318

Dankers R, Feyen L (2009) Flood hazard in Europe in an ensemble of regional climate scenarios. J Geophys Res 114(D16):D16108. doi:10.1029/2008JD011523

Das S, Simonovic SP (2012) Assessment of uncertainty in flood flows under climate change impacts in the Upper Thames River Basin, Canada. Br J Environ Clim Chang 2(4):318-338 
Eisner S, Voss F, Kynast E (2012) Statistical bias correction of global climate projections- consequences for large scale modeling of flood flows. Adv Geosci 31:75-82

Emissions Scenarios: IPCC Special Report (2000). In: Nakicenovic N, Swart R (eds). Cambridge Univ. Press, Cambridge

Garraway M (2011) Guide for Assessment of Hydrologic Effects of Climate Change in Ontario \& Future Climate Change Data Sets, 1-19

Gaur A, Simonovic SP (2013) Climate Change Impact on Flood Hazard in the Grand River basin. Water Resources Research Report no. 084, Facility for Intelligent Decision Support, Department of Civil and Environmental Engineering, London, Ontario, Canada, 92 pages. ISBN: (print) 978-0-7714-3063-3; (online) 978-0-7714-3064-0

Haerter JO, Hangemann S, Moseley C, Piani C (2011) Climate model bias correction and the role of timescales. Hydrol Earth Syst Sci 15:1065-1079. doi:10.5194/hess-15-1065-2011

Hempel S, Frieler K, Warszawski L, Schewe J, Piontek F (2013) A trend-preserving bias correction - the ISIMIP approach. Earth System Dynam 4(2):219-236. doi:10.5194/esd-4-219-2013

Hirabayashi Y, Kanae S, Emori S (2009) Global projections of changing risks of floods and droughts in a changing climate. Hydrol Sci J 53(4):754-772

Hirabayashi Y, Mahendran R, Koirala S, Konoshima L, Yamazaki D et al (2013) Global flood risk under climate change. Nat Clim Chang 3(9):816-821. doi:10.1038/nclimate1911

Ines AVM, Hansen JW (2006) Bias correction of daily GCM rainfall for crop simulation studies. Agric For Meteorol 138(1-4):44-53. doi:10.1016/j.agrformet.2006.03.009

Intergovernmental Panel on Climate Change (IPCC) (2007) Climate Change 2007: The Physical Science Basis. Contribution of Working Group I to the Fourth Assessment Report of the Intergovernmental Panel on Climate Change. In: Solomon S, Qin D, Manning M, Chen Z, Marquis M, Averyt KB, Tignor M, Miller HL (eds). Cambridge University Press, Cambridge and New York, 996 pp

Intergovernmental Panel on Climate Change (IPCC) (2013) Climate Change 2013: The Physical Science Basis. Contribution of Working Group I to the Fifth Assessment Report of the Intergovernmental Panel on Climate Change. In: Stocker TF, Qin D, Plattner G-K, Tignor M, Allen SK, Boschung J, Nauels A, Xia Y, Bex V, Midgley PM (eds). Cambridge University Press, Cambridge and New, 1535 pp, doi:10.1017/ CBO9781107415324

Khan MS, Coulibaly P, Dibike Y (2006) Uncertainty analysis of statistical downscaling methods. J Hydrol 319(1-4):357-382. doi:10.1016/j.jhydrol.2005.06.035

King LM, Mcleod AI, Simonovic SP (2012) Simulation of historical temperatures using a multi-site, multivariate block resampling algorithm with perturbation. Hydrol Process 28(3):905-912. doi:10.1002/hyp

Knutti R, Sedlacek (2013) Robustness and uncertainties in the new CMIP5 climate model projections. Nat Clim Chang 3:369-373. doi:10.1038/NCLIMATE1716

Lapp S, Sauchyn D, Wheaton E (2008) Institutional adaptations to climate change project : future climate change scenarios for the South Saskatchewan River Basin

Maxino CC, Mcavaney BJ, Pitman AJ, Perkins SE (2008) Ranking the AR4 climate models over the MurrayDarling Basin using simulated maximum temperature, minimum temperature and precipitation. Int $\mathrm{J}$ Climatol 28:1097-1112. doi:10.1002/joc.1612

Meehl GA, Covey C, Taylor KE et al (2007) THE WCRP CMIP3 Multimodel dataset: a new era in climate change research. Bull Am Meteorol Soc 88(9):1383-1394

Mortsch L (2011) Climate change scenarios for application in water resources impact and adaptation assessments. Workshop on Probabilistic assessment of regional changes in climate variability and extremes. Montreal, Quebec

Perkins SE, Pitman AJ, Holbrook NJ, McAneney J (2007) Evaluation of the AR4 climate models' simulated daily maximum temperature, minimum temperature, and precipitation over Australia using probability density functions. J Clim 20(17):4356-4376. doi:10.1175/JCLI4253.1

Perkins SE, Pitman AJ, Sisson SA (2009) Smaller projected increases in 20-year temperature returns over Australia in skill-selected climate models. Geophys Res Lett 36(6):L06710. doi:10.1029/2009GL037293

Piani C, Haerter JO, Coppola E (2009) Statistical bias correction for daily precipitation in regional climate models over Europe. Theor Appl Climatol 99(1-2):187-192. doi:10.1007/s00704-009-0134-9

Piani C, Weedon GP, Best M, Gomes SM, Viterbo P, Hagemann S, Haerter JO (2010) Statistical bias correction of global simulated daily precipitation and temperature for the application of hydrological models. J Hydrol 395(3-4):199-215. doi:10.1016/j.jhydrol.2010.10.024

Pitman AJ, Perkins SE (2008) Regional projections of future seasonal and annual changes in rainfall and temperature over Australia based on skill-selected AR4 models. Earth Interact 12:1-50. doi:10.1175/2008EI260.1

Sakaguchi K, Zeng X, Brunke MA (2012a) Temporal- and spatial-scale dependence of three CMIP3 climate models in simulating the surface temperature trend in the twentieth century. J Clim 25(7):2456-2470. doi:10. 1175/JCLI-D-11-00106.1

Sakaguchi K, Zeng X, Brunke MA (2012b) The hindcast skill of the CMIP ensembles for the surface air temperature trend. J Geophys Res 117(D16):D16113. doi:10.1029/2012JD017765 
Schneider C, Laizé CLR, Acreman MC, Flörke M (2012) How will climate change modify river flow regimes in Europe? Hydrol Earth Syst Sci Discuss 9(8):9193-9238. doi:10.5194/hessd-9-9193-2012

Srivastav R, Simonovic SP (2014) Multi-site, multivariate weather generator using maximum entropy bootstrap. Clim Dyn. doi:10.1007/s00382-014-2157-x

Taye MT, Willems P (2013) Influence of downscaling methods in projecting climate change impact on hydrological extremes of upper Blue Nile basin. Hydrol Earth Syst Sci Discuss 10(6):7857-7896. doi:10. 5194/hessd-10-7857-2013

Tebaldi C, Knutti R (2007) The use of the multi-model ensemble in probabilistic climate projections. Philosophical Transactions. Ser A Math Phys Eng Sci 365(1857):2053-2075. doi:10.1098/rsta.2007.2076

Vannitsem S (2011) Bias correction and post-processing under climate change. Nonlinear Process Geophys 18(6):911-924. doi:10.5194/npg-18-911-2011

Vuuren D, Edmonds J, Kainuma M, Riahi K, Thomson A, Hibbard K, Hurtt G et al (2011) The representative concentration pathways: an overview. Clim Chang 109(1-2):5-31. doi:10.1007/s10584-011-0148-z 